\title{
Nocturno de Chile y el canon
}

\author{
Nocturno de Chile and the canon
}

ROBERTO GONZÁLEZ ECHEVARRÍA

Yale University. New Haven, Estados Unidos

r.gonzalezechevarria@yale.edu

\begin{abstract}
Cufrimos la nostalgia del Boom. ¿Cuándo va a surgir el próximo García Márquez? ¿Por qué no han aparecido ni un nuevo Borges ni otro Carpentier? Nos consolamos o decepcionamos con la última novela de Vargas Llosa o Fuentes, o aun alguna del propio autor de Cien años de soledad. Nos entusiasmamos con libros prometedores de escritores jóvenes. Pero no es suficiente. Los que tuvimos la dicha de formarnos en los años sesenta del siglo pasado recordamos una época en que con vertiginosa frecuencia aparecían nuevos valores y se publicaban inesperadas obras maestras, como Paradiso, extraordinaria novela de un gran escritor del que apenas habíamos oído hablar, y que los que lo conocían consideraban poeta. En los mismos sesenta una nueva generación irrumpió puntualmente en América Latina, con figuras de la talla de Sarduy y Puig, dándonos así la sensación de que la pachanga iba a ser permanente. Pero no fue así. Esa nueva generación se malogró a causa del SIDA, y el llamado post-boom (sobre el que ya hay varios libros), fue una detonación en sordina. Seguimos, como los judíos, esperando la llegada del mesías. El chileno Roberto Bolaño, quien, con trágica disposición para serlo, murió joven (de 50 años; sus fechas son 1953-2003), es el único narrador latinoamericano reciente cuyos éxitos en nuestro ámbito y el extranjero nos recuerdan los del Boom, y anuncian tal vez la llegada de una nueva era de esplendor.

La irrupción de Bolaño me ha hecho plantearme otra vez un problema que me ha hostigado durante los últimos años: ¿Cómo hacemos juicios de valor literario? ¿En qué principios nos basamos, y en qué se apoyan esos principios? Mi obsesión parte de razones tanto prácticas como teóricas. Muchos aquí somos críticos de la literatura del presente, ya sea escribiendo reseñas
\end{abstract}


en publicaciones periódicas, como decidiendo qué debe o no publicarse en las editoriales. Hasta en nuestras rutinarias tareas docentes somos llamados a, como decía Martí, "ejercer el criterio", preparando listas de lecturas para exámenes doctorales, o diseñando cursos nuevos sobre la literatura actual. En todos estos casos hay que escoger, como decían los existencialistas, porque no se les puede dar cabida a todos. Es cierto que a veces las ideologías o las tendencias críticas nos inclinan en favor de ésta o aquella obra, como si no interviniera el gusto, pero siempre hay un juicio de valor implícito. Además, y éste es ya un planteamiento teórico aunque basado en la práctica, la experiencia nos enseña que por mucho que se promueva o se denigre a un autor, a la larga hay un consenso que no permite que nadie se vaya a atrever a sacar a Neruda del canon por haber sido comunista, o a Borges por haber sido conservador. Y obras que en un momento fueron aclamadas por razones políticas, como Me llamo Rigoberta Menchú, van cayendo en el olvido que se merecían. Hay como un criterio general, una especie de razón crítica, y aludo por supuesto a Kant, que sobrepasa el de cada uno de nosotros, que se va sedimentando a base de muchas opiniones y preferencias acumuladas. Voy a hablar hoy de una obra de Bolaño que, como casi todas las suyas, ha sido recibida con aplausos, Nocturno de Chile-publicada en el año 2000.

¿En qué consiste Nocturno de Chile? Es la confesión, durante una noche entera de fiebre, de un sacerdote chileno, crítico literario, poeta menor y miembro del Opus Dei, que se cree al borde de la muerte y narra su vida, especialmente los años que van desde antes de la dictadura de Pinochet, hasta -pasando por ésta- la llegada de la democracia. Acodado sobre la cama, Sebastián Urrutia Lacroix, ésos son su nombre y apellidos, relata su vocación religiosa y literaria, sus viajes por Europa, pero sobre todo sus relaciones con un viejo e influyente crítico literario cuyo sobrenombre es Farewell, que es su mentor, y con escritores chilenos sobre los que ha hecho críticas y tiene amistad. Sebastián además dramatiza su trato tenso e intenso con "el joven envejecido", personaje inventado por él que representa su conciencia, que lo reta frecuentemente sobre su conducta, y en respuesta de cuyas acusaciones hace su confesión. Este psicodrama conduce al momento culminante del relato, la anagnórisis final con la que cierra esta breve novela de 150 páginas.

En ensayos recientes he intentado fijar criterios que me sirven, a priori, para evaluar una obra nueva; nueva porque los clásicos, o las obras que hoy diríamos son canónicas, ya vienen dotadas de una aureola que interfiere con el proceso de valoración ${ }^{1}$. Juzgar una obra a base de estos criterios es, para

${ }^{1}$ Recogidos en Oye mi son: ensayos y testimonios sobre literatura hispanoamericana (2008). 
mí, un gesto kantiano. Digo gesto porque no se trata, ni con mucho, de la aplicación rigurosa de la filosofía de Kant, cuyas críticas se centran más en la cuestión del conocimiento que en el de la apreciación estética, mientras que mi propósito es precisamente el de juzgar la calidad del texto y decidir si merece o no elevarse a ese canon cuya existencia debemos a Harold Bloom (1994). Semejante juicio conlleva, por supuesto, el conocimiento del texto, pero en la aproximación que planteo ese conocimiento forma parte integral de la evaluación misma, es consustancial con ella. La obra considerada valiosa se deja conocer porque exhibe calidades que se ajustan a mis criterios de evaluación. Esto forma parte también del gesto kantiano de que hablo y parte del presupuesto de que hay un conocimiento evaluativo general que supera mi propia experiencia crítica y que guía a ésta a la práctica de la lectura; se trata del consenso de que hablaba antes, que consolida un canon que explícita o tácitamente todos aceptamos y que contiene los valores generales que aplico a la obra nueva. Me atrae de Kant el equilibrio que propone entre la experiencia, la práctica y categorías ideales. Hay en todo esto una aparente circularidad: esta obra es buena porque es buena. Digo aparente porque ese canon virtual existe objetivamente antes de la aparición de la obra que nos aprestamos a evaluar y de mi propia evaluación. Quiero desesperadamente evitar los determinismos ideológicos al uso sin caer en el puro impresionismo.

Retomo aquí lo dicho en algunos de esos ensayos mencionados sobre mis criterios de evaluación literaria. Sé que éstos pueden parecer muy personales, pero mi propia persona constituye el límite de lo que sé como suma de mis lecturas y resta de mis incapacidades, balance de la memoria, de sus fallas, y de la experiencia vital. Además son criterios que, a pesar de su aspecto personal, supongo muchos, si no la mayoría comparten de forma tácita, y que por lo tanto pueden servir de primera aproximación. Lo personal, en tanto que propiedad común antes que algo exclusivamente propio, puede ser y es compartible, y donde no lo es, apto a ser corregido; este elemento pragmático también se remite a Kant. En mi caso, me gustaría pensar que la mayoría de mis juicios han ido siendo corroborados con el pasar del tiempo y la aceptación de categorías que no se deben, desde luego, únicamente a mí, sino a preferencias que se han establecido por la circulación continuada de obras y la desaparición de otras que no han resistido la prueba del tiempo, que no es más que el resultado de las preferencias de críticos, editores y lectores. Para mí los casos paradigmáticos han sido Severo Sarduy y Reinaldo Arenas, que se han impuesto a pesar de los prejuicios políticos, sexuales y estéticos de los comisarios cubanos y sus acólitos. Del otro lado no sólo se 
encuentran los muchos mediocres promovidos por la crítica oficialista cubana que han caído en merecido olvido, sino hasta estrellas fugaces como el poeta nicaragüense Ernesto Cardenal, que se ha ido apagando a medida que el movimiento político a cuyo reflejo brillaba se extinguía. Los escritores ya clásicos que he estudiado, como Alejo Carpentier, han seguido (y seguirán), por supuesto, en el lugar prominente que les corresponde. Pero la última novela de éste, La consagración de la primavera, que consideré desde el principio deficiente (no fui el único), no ha tenido resonancia ninguna. Con otros consagrados me he equivocado. Rayuela, por ejemplo, me deslumbró al principio, pero hoy se me cae de las manos, y me temo que de Cortázar van a quedar algunos cuentos, pero nada más. El silencio que se cierne en torno a Cortázar hoy me parece que corrobora lo anterior.

Los cinco criterios que propuse en los ensayos mencionados, y que me propongo aplicar hoy a Nocturno de Chile, son los siguientes. Primero: la obra debe tener elevación, altura, en el sentido que le da Longino al término, por los temas de que se ocupa, que son los grandes de siempre, que enumerados dan la impresión de banales, pero esto es sólo un (d)efecto retórico: el amor, la muerte, la culpa, la injusticia, el deseo de trascendencia. Suenan huecos porque lo decisivo es cómo se plasman en la obra, pero de todos modos son ellos los que le dan aliento y grandeza, que no tiene que ser estrictamente material por cierto. Hay insoportables novelones de mil páginas y relatos extraordinarios de diez. Segundo: prefiero obras que revelan su urdimbre literaria, pero con cierto recato, como Cien años de soledad y el Quijote, y muchas novelas vanguardistas. Es aquí donde se aloja la ironía, donde la obra y su autor le hacen un guiño al lector para recordarle que se trata de una ficción, y que esto mismo es tema importante de la obra que lee porque remite a la imperfecta condición humana y su parcial y muy limitado conocimiento de la realidad y de uno mismo. Tercero: las obras que me impresionan siempre se reservan un secreto que no podemos descifrar aunque nos provoca instándonos a interpretarlo, pero a la postre nos elude. Creo que ese secreto escapa también a la conciencia del escritor, que se para ante él en condición análoga a la del lector. Es como un residuo, un suplemento, para invocar a Derrida, tal vez el origen mismo del texto, que presume ser determinante; principio en todo sentido. Al tratar de conocerlo dialogan el subconsciente del escritor y el del lector o crítico, y es de ese diálogo que emana el texto de este último, que tiende en ciertos momentos también a tornarse enigmático (ma non troppo, per piacere). Cuarto: las obras importantes reciclan la tradición recibida, pero no únicamente la nacional o 
local, sino la universal. Es su sello de originalidad, su marca de fábrica, por así decir. No concibo esa relación como lucha agónica entre el nuevo escritor y sus precursores, según la teoría de mi gran amigo Bloom, sino como algo más benigno, que puede surgir, por el contrario, del ansia del nuevo escritor de encontrar amparo a la sombra de una obra clásica, pero añadiéndole un toque personal que en el mejor de los casos se convierte en algo sublime en sí, no en relación con ésta. Estimo que es lo que ocurre con Cien años de soledad, en la que se perciben ecos de Faulkner, de Carpentier, de la tragedia griega, de Cervantes, de los cuentos de Borges, y de muchas obras que García Márquez mismo menciona en el texto. Pero la armazón de relojería de esa gran obra, que indica la presencia de un destino minuciosamente señalado y fatal, cómico y trágico a la vez, es única y suya propia, además perfectamente reconocible en cualquiera de sus oraciones, desde la primera hasta la última. Quinto, y último criterio: la obra debe tener prosa, o poesía, si se trata de un poema, la marca de que acabo de hablar -estilo propio. Hay escritores sin estilo, pero apenas podemos llamarlos tales. Tal vez todo se supedita, si somos materialistas, a la vibración de ondas cerebrales que dirigen los períodos sintácticos y el orden de las palabras -colocación de adjetivos, formas y tiempos verbales. El ritmo de una prosa o de un poema lo constituyen esas elecciones, que hacen el estilo de Proust, por ejemplo, inigualable y reconocible antes de llegar al final de la oración -que tarda en llegar, como sabemos. Claro, como estos criterios se refieren a atributos entretejidos simultáneamente entre sí, el estilo tiene que estar a tono con el tema, con los coqueteos de ese enigma que nos elude, con la elevación de la obra, y así sucesivamente. Cuando no, como ocurre en obras como el Ulises de Joyce, y en la de discípulos suyos como Cabrera Infante, el efecto que se persigue surge de la disonancia, que es entonces, paradójicamente, una forma de armonía.

Primero. Nocturno de Chile trata de temas trascendentales, como la muerte, a la que parece abocado el protagonista-narrador, también la fe religiosa, la vocación literaria y la naturaleza misma de la literatura y la crítica. También está atravesada por el sentido de la culpa, la persistencia del mal y la complicidad de literatos e intelectuales con éste. Desde su título mismo, Nocturno de Chile anuncia una reflexión profunda, meticulosa y sostenida sobre la patria, sobre la nación. Digo meticulosa porque hay, en el discurso del narrador, no sólo una amplia revisión de la literatura chilena, donde aparecen mencionadas generaciones de escritores modernos, algunos actuales, y otros de épocas anteriores, como Alberto Blest-Gana, y la recapitulación de 
la historia reciente de Chile, sino una considerable cantidad de chilenismos, casi como si se tratara de un retorno a la literatura costumbrista ${ }^{2}$. En última instancia, el tema central de Nocturno de Chile es la esencia de la literatura y su fragua en una conciencia lúcida, atravesada de literatura, historia, filosofía, teología, pero también de curiosidad por la condición de esa misma conciencia creadora, que se presenta en el momento (y movimiento) dramático de su posible extinción, y monta un psicodrama en que se divide en los dos personajes mencionados, el protagonista-narrador, y el "joven envejecido", su conciencia, que el postrado parlante identifica como un yo anterior más puro, que no ha cedido a las tentaciones y coerciones del mal, y que lo interpela, según dice, porque éste nunca "habla". Al final, en la anagnórisis que constituye el desenlace, el narrador dice descubrir que ese "joven envejecido" sigue siendo él mismo -es decir, el que ha escrito la novela.

En lo relativo a la altura, Nocturno de Chile no sólo la alcanza por sus trascendentales temas, sino que juega con el concepto mismo longiniano, cumpliendo así además con el requisito de mostrar su urdimbre literaria. Me refiero a la serie de episodios cuando a Sebastián lo envían a Europa para estudiar la preservación de las iglesias. Descubre que el deterioro de éstas se debe principalmente a las cagadas de las palomas, y que el método con que se las combate es la cetrería; cazarlas con halcones especialmente adiestrados. Hay un elemento satírico aquí del nacionalismo porque el nombre del halcón guardián de cada iglesia remite a alguna característica nacional, ya sea italiano, alemán o belga. El español, que protege la catedral de Burgos se llama, inevitablemente "Rodrigo", y uno francés "Ta Gueule". (El cubano debía llamarse "La Tuya"). Me parece que estos halcones y sus vuelos son una alusión irónica a Longino y sus teorías de lo "sublime", de la elevación o altura, y los episodios particulares despliegan, además, un acentuado tono literario, una subida de tono retórico. Creo escuchar además en esa "cetrería de palomas" un eco deformado de la mística ("volé tan alto, tal alto / que le di a la caza alcance"). Todo esto es muy irónico porque se lleva a cabo para contener la lluvia de cagadas que las palomas descargan sobre las iglesias, y que anuncia la "tormenta de mierda" de la última y profética oración de la novela. La relevancia (valga la palabra) de estos episodios aumenta si tomamos en cuenta que la paloma simboliza el Espíritu Santo en la doctrina católica. (Hay un amplio simbolismo ornitológico en Nocturno de Chile que no puedo analizar aquí). El Espíritu Santo, y hay una paloma blanca, se caga en

\footnotetext{
${ }^{2}$ Once, fundo, chupallas de paja, paltos, congrio, araucaria, eschumizado, chitas, roteque, guata, culear, picos, huevón, machas, micros, copuchentos, cartucho, etc.
} 
la iglesia católica -literalmente en las iglesias católicas- provocando la ruina de ésta, o mejor de éstas. Es una profecía escatológica en todos sentidos; un apocalipsis fecal, o una escatología escatológica.

Segundo. En cuanto a revelar su contextura literaria, y por lo tanto asumir un tono reflexivo, irónico, Nocturno de Chile lo hace de forma "natural", si semejante cosa es posible, porque es la confesión no sólo de un sacerdote, sino de un crítico literario, muy consciente de la elaboración de su discurso. En Nocturno de Chile no hay metatexto, es decir, no hay nada que indique qué es lo que leemos, la ilusión sería que es un bloque de texto en bruto, no sometido a las reglas de la literatura, ni siquiera a las de la puntuación. Pero esto mismo, desde luego, es prueba de lo contrario. Ya hemos visto en los episodios de las palomas, como dije, una revelación del cariz literario del texto. Pero, además, de lo que no hay duda es que lo que leemos contiene fragmentos separables, antológicos, en algunos casos sublimes, como la visión, hacia el final, del Padre Antonio y el Árbol de Judas. El texto es tan literario en su forma y contenido porque el protagonista-narrador es un individuo inmensamente culto. Por ejemplo, el llamado "joven envejecido" es un eco del tópico clásico del puer senex, estudiado por Ernst Robert Curtius (Sebastián es lector asiduo de los clásicos griegos y latinos). Pero la urdimbre literaria se manifiesta también en la narración de varias historias, con personajes sacados de la vida real, supuestamente contados por otros personajes, como Farewell o Salvador Reyes, que son como pasajes de una novela o relato en ciernes.

Por ejemplo, en la historia de Ernst Jünger en el París ocupado por los alemanes, entrelazada con la de un pintor guatemalteco anoréxico, el narrador goza de una omnisciencia con respecto a éstos personajes como sólo podría tenerla un novelista valiéndose de los consabidos recursos y licencia literarios. Lo mismo ocurre con el dramático relato final, sobre la escritora chilena María Canales, en que llega a su apogeo la temática de la complicidad entre la literatura y el mal, y que leemos a sabiendas de que es como el borrador de una novela o relato futuro que el protagonista prepara. El contrapunto entre literatura e inmoralidad se manifiesta en pasajes brillantes en que se alternan los acontecimientos de la vida política con las lecturas del protagonista, pero sobre todo en ese relato final, especie de transgresión culminante: la historia de las reuniones literarias en la mansión de Canales, casada con un agente norteamericano que resulta ser colaborador de la DINA (el servicio de inteligencia de Pinochet), que propicia la persecución y tortura de disidentes. Estás últimas se realizan en el sótano de la casa de las veladas, a veces durante la celebración de éstas. Cuando, con la caída de 
Pinochet, se descubre todo, muchos de los escritores niegan haber asistido a las reuniones. En este sentido Nocturno de Chile es también una especie de confesión política. Al final, la verdad que emerge respecto a todo esto no es, por supuesto, clara y tajante, y se expresa más bien en la desolación, el abandono, de la escritora, una vez que se descubre su complicidad con las atrocidades de la dictadura. Canales se percata, en el relato que nos cuenta el narrador, que es en esa situación de desarraigo, complicidad, conciencia de culpa y obstinación en el mal que se da la creación literaria -que la culpa es consustancial con ella. Sebastián se abstiene de juzgarla y, como sacerdote, quiere absolverla. En última instancia esta es la visión a la que tiene acceso el protagonista en su noche de pesadillas y alucinaciones mientras, enfermo, se cree al borde de la muerte. Es también, a mi parecer, lo que le da el título a la obra. Nocturno de Chile alude, por supuesto, al "Nocturno" de José Asunción Silva, que Sebastián recita una noche en el barco que lo transporta a Italia, para deleite de los pasajeros y la tripulación, y como guiño al lector cómplice, imbuido en literatura. Pero "nocturno" aquí quiere más bien decir "pesadilla de Chile", "imagen onírica de Chile".

Tercero. El secreto que una obra guarda para mí puede muy bien ser aquel punto donde más claramente se manifiesta mi propia ignorancia o, para usar la terminología de Paul de Man, mi ceguera -que yo quisiera fuera compensada con algo de visión. Esta ceguera puede ser congénita, ignorancia innata, o producto de los defectos de mi formación: las enormes lagunas culturales que todos tenemos. Pero tal vez mi incapacidad abra el espacio donde dialoguen mi flaca conciencia crítica y el poderoso subconsciente de Bolaño, con su personaje crítico literario como emblema o fetiche de esa práctica compartida. Será necesariamente un diálogo de sordos, o un nocturno mutuo al que doy expresión muy alerta de su probable falsedad. Para mí ese punto ciego está en la temática fascista, sugerida por la pertenencia del protagonista al Opus Dei. Es una historia en que parece plasmarse algo así como el origen del fascismo, pero que apenas puedo descifrar. Es la de un zapatero austriaco (¿alusión a Hitler?) a quien se le ocurre crear un parque en loor de los héroes, en el que en la falda de una montaña, se esculpen monumentales estatuas de éstos. Pero muere el zapatero, el parque cae en un descuido total, y termina siendo demolido por las tropas soviéticas que ocupan la región durante la Segunda Guerra Mundial. En el relato de la elaboración de la obra (opus) hay como una historia sesgada de la creación de la obra literaria con todos sus pormenores y angustias, que podría ser el cuento de cómo Bolaño concibe ese proceso, inclusive el de la obra misma que leemos: 
cuando el zapatero yacía rendido, enredado entre las sábanas, a veces sin siquiera desvestirse del todo entregado a su sueño obsesivo, marchando a través de sus pesadillas, al final de las cuales lo esperaba siempre la Colina de los Héroes, grave y quieta, oscura y noble, el proyecto, la obra de la que conocemos sólo fragmentos, la obra que a menudo creemos conocer pero que en realidad conocemos muy poco, el misterio que llevamos en el corazón y que en un momento de arrebato ponemos en el centro de una bandeja de metal labrada con caracteres micénicos, unos caracteres que balbucean nuestra derrota, la justa en donde hemos caído y no lo sabemos, y nosotros hemos puesto el corazón en medio de esa bandeja fría, el corazón, el corazón, y el zapatero se estremecía en el lecho (59).

El trasiego de la primera a la tercera persona, del discurso del protagonista-narrador al del zapatero, la posición de éste en la cama, sugieren una confesión personal sobre la creación literaria, de la obra-subrayo obra para referirme al Opus. La historia del zapatero podría ser, en breve, una alegoría de la escritura en cuya base hay una mezcla de fe, dedicación y alabanza de la patria y sus tradiciones que se aproxima al fascismo. Pero no puedo entender del todo la figura del zapatero, qué tiene que ver su profesión con su anhelo de crear el parque, y cómo se vincula todo esto a la temática chilena, aunque podría ser una reflexión sobre la dictadura de Pinochet, como bien puede haber paralelismos entre el París ocupado por los nazis, y el Santiago de Sebastián, con sus toques de queda. Esta historia es, para mí, como un secreto vedado, pero que puede contener la clave del origen mismo de Nocturno de Chile, que me elude a mí como también posiblemente a Bolaño, por eso habla "del misterio que llevamos en el corazón".

Cuarto. En Nocturno de Chile se recicla o filtra la tradición literaria recibida, pero no únicamente la nacional o local, sino la universal. (Sé que "reciclar" o "filtrar" son metáforas manidas, tal vez inútiles ya, mejor sería decir se hace consustancial con la tradición recibida). Debo decir que, en la mejor tradición de la literatura latinoamericana -Garcilaso el Inca, Sigüenza, Sor Juana, Bello, Martí, Carpentier, Neruda, Borges y Paz- Bolaño es un escritor muy docto, con toda la cultura occidental en la cabeza. La alusión al "Nocturno" de Silva vendría a representar la literatura latinoamericana que el narrador ha absorbido; no hay que olvidar nunca que el protagonista es un crítico literario con una formación vastísima. Pero la novela es también una reflexión sobre la literatura chilena, desde la más canónica hasta la de más palpitante actualidad. Ésta -la literatura chilena- pasa por la conciencia crítico-creadora de Sebastián para plasmarse en el texto que escribe. Salvo 
Farewell, el viejo crítico que Sebastián, el protagonista, quiere ver como su mentor, los escritores chilenos, desde Neruda y Parra hasta Lafourcade y Lihn, aparecen todos con sus nombres propios. Nocturno de Chile no es un roman à clef, sino un ajuste de cuentas de la literatura chilena consigo misma, y de la relación de ésta con la política. Al nivel más abstracto la novela delata la complicidad de la literatura con el mal. Porque lo que asedia a Sebastián es un agudo sentido de culpa, de la suya propia y la de otros escritores, paliado por su vocación religiosa que lo inclina a la misericordia y el perdón. Este remordimiento encarna en la figura del "joven envejecido", que tal vez quiera ser figura del Bolaño novelista real, un autorretrato. En lo concerniente a la historia de Chile en relación a la literatura, específicamente la era que va desde el triunfo electoral de Allende hasta la llegada de la democracia tras la derrota de Pinochet, la narrativa es prolija en detalles sobre la vida en Santiago, y los protagonistas, a algunos de los cuales, como Pinochet y su Junta, llega a conocer en condiciones extraordinarias -lo contratan para darles clases de marxismo. El intelectual al servicio del poder.

En cuanto a la literatura occidental hay una fuerte presencia de las Confesiones de San Agustín, justificada por el hecho de que el protagonista-narrador es sacerdote, y dice haber leído a San Agustín en el seminario, entre otros padres de la iglesia. Desde el principio sabemos que la autoridad suprema a quien apela en su confesión es Dios mismo, aunque no se dirige directamente a él como San Agustín, sino que el diálogo se queda dentro del drama de su propia conciencia. Pero, aparte de la temática religiosa agustiniana (pecado, culpa, penitencia, inclinación humana hacia el mal) el asunto central es, como en las Confesiones del santo, la escritura. Aquí, y en su enunciado, el narrador apela a la fórmula agustiniana, adaptada por Dante de confesiónconversión-poesía, sólo que aquí la conversión es el final mismo del texto. Es decir, el proceso de conversión conllevaría no sólo redimirse y reformarse sino a la práctica de la escritura. Dante está presente a través de la reiterada figura de Sordello, personaje clave con el que parece identificarse el narrador, del que supo sólo por Farewell pero que sigue resonando en su texto en versiones deformadas como Sordel. (Esto suena a "sórdido él", es decir, "sórdido yo"). Sordello, que aparece en los cantos VI y VII del Purgatorio fue un trovador nacido en Italia, pero que escribió en provenzal y tuvo una actividad política (y amatoria, por cierto) notable, a quien Dante le concede un lugar de honor en el Purgatorio, semejante al de Farinata en el Infierno y Cacciaguida en el Paraíso. La aparición de Sordello provoca una diatriba del peregrino-narrador de la Comedia sobre la situación política de la Italia de su tiempo. En Nocturno de Chile aparece como un antepasado remoto del 
protagonista, cogido en una encrucijada política y literaria similar a la suya -particularmente su relación con la figura virgiliana de Farewell. Lo que se sugiere con esta alusión a Dante, evidentemente, es que la diatriba contra la política italiana podría hacerse contra la chilena de los años setenta, y que Nocturno de Chile es o podría haber sido esa diatriba.

Quinto: la obra debe tener prosa, estilo. Ya he dicho varias veces que el protagonista-narrador, siendo crítico, poeta, y cultísimo, se expresa en un estilo literario pulido, elevado, dúctil, con oportunas alusiones al arte, la filosofía, y la literatura. También he mencionado que algunas de las historias que cuenta parecen borradores de relatos o novelas futuras. Me he referido, además, a pasajes sublimes, antologizables, longinianos (sabemos que Longino prefería el fragmento). Ninguno, tal vez, tan juguetón, lleno de recursos retóricos y poéticos, y con un ritmo prosódico, sintáctico, afín a lo que narra, como éste, en que se describe un baile de salón:

Otras veces discernía a un grupo de figuras cogidas por la cintura, como si bailaran la conga, desplazarse a lo largo y ancho de un salón cuyas paredes estaban atiborradas de cuadros. Baile, padre, me decía alguien a quien yo no veía. No puedo, respondía, los votos no me lo permiten. Yo tenía un cuadernillo en una mano y con la otra escribía un esbozo de reseña literaria. El libro se llamaba El paso del tiempo. El paso del tiempo, el paso del tiempo, el crujidero de los años, el despeñadero de las ilusiones, la quebrada mortal de los afanes de todo tipo menos el afán de la supervivencia. La serpiente sincopada de la conga indefectiblemente se acercaba a mi rincón, moviendo y levantando al unísono primero la pierna izquierda, luego la derecha, luego la izquierda, luego la derecha, y entonces yo distinguía a Farewell que asía por la cintura a una señora de la mejor sociedad chilena de aquellos años, una señora de apellido vasco que desgraciadamente he olvidado, mientras él, a su vez, era asido por la cintura por un anciano cuyo cuerpo estaba a punto de desmoronarse, un viejo más muerto que vivo pero que sonreía a diestra y siniestra y que parecía disfrutar de la conga como el que más (34-35).

Nótese que hay en esa escena, además, una alusión a las "danzas de la muerte" medievales. Pero los aciertos estilísticos comienzan desde las primeras oraciones, desde la apertura misma de la novela: "Ahora me muero, pero tengo muchas cosas que decir todavía" (11). En ese juego de adverbios de tiempo -"ahora", "todavía" - está contenida ya toda la obra.

A estas alturas (valga -otra vez- la palabra) resulta superfluo decir que, 
en efecto, creo que Nocturno de Chile permanecerá en el canon de la literatura latinoamericana, y en el de la occidental. Es una pequeña obra maestra al nivel, y a veces por encima del nivel, de lo mejor que escribieron los novelistas consagrados del canon -los del Boom. Pienso que Bolaño es mejor novelista que José Donoso, para ponerlo en un contexto estrictamente chileno. (El fantasma de mi amigo Pepe me va a salir esta noche para halarme el dedo gordo del pie). Me declaro admirador de Bolaño y me apresto gozoso a estudiar su obra gruesa.

\section{REFERENCIAS}

Bloom, Harold. 1994. The western canon: the books and school of the ages. Nueva York: Harcourt Brace.

Bolaño, Roberto. 2000. Nocturno de Chile. Barcelona: Anagrama.

Burgos-Debray, Elisabeth. 1983. Me llamo Rigoberta Menchú y asi me nació la conciencia. La Habana: Casa de las Américas.

Carpentier, Alejo. 1978. La consagración de la primavera. México: Siglo Veintiuno.

Cortázar, Julio. 1963. Rayuela. Buenos Aires: Sudamericana.

García Márquez, Gabriel. 1967. Cien años de soledad. Buenos Aires Sudamericana.

González Echevarría, Roberto. 2008. Oye mi son: ensayos y testimonios sobre literatura hispanoamericana. Sevilla: Renacimiento.

Lezama Lima, José. 1966. Paradiso. La Habana: Ediciones Unión.

Silva, José Asunción. 1951. Nocturno. Bogotá: Prensas del Ministerio de Educación Nacional. 